\title{
Partial Shading Condition on PV Array: Causes, Effects and Shading Mitigation using DSMPPT
}

\author{
Prateek Mundra, Anoop Arya, Suresh K Gawre
}

\begin{abstract}
Solar photovoltaic (PV) systems are gaining importance increasingly as it directly converts solar radiation into electrical energy which is renewable and environment friendly. Where it has a numerous advantage, some disadvantages are also there like its dependency on environmental conditions. The power developed by solar panel decreases if it does not get uniform radiation. Sometimes due to nearby buildings, passing clouds etc. PV module might be partially shaded because of which power output of solar panel may get decrease this is called partial shading conditions. It causes significant reduction in the system power output. To overcome this, maximum power point-tracking under partial shading condition by continuous duty cycle variation schemes have been proposed, in which dc-dc boost converters are connected to PV module to enable maximum power extraction. In this paper a new method of Duty Sweep Maximum Power Point Tracking (DSMPPT) has been implanted, which is capable of tracking the Global Maximum Power Point (GMPP) in the presence of other local maxima. The proposed scheme tracks Maximum Power Point (MPP) by continuous variation of converter's duty cycle without the use of costly components such as signal converters and microprocessors thereby increasing the compactness of the system.
\end{abstract}

Keywords: Photo voltaic, Partial Shading, DSMPPT

\section{INTRODUCTION}

Electrical energy is the most unprecedented inventions of all times. The growing requirement for electricity and inadequate amount of fossil fuel diverts our attention towards renewable sources of energy. Therefore, multiple researches are going on to create power from sustainable power sources like wind, hydro, solar, geothermal and tidal etc. Recently electricity generation from solar photovoltaic is becoming popular as it is free of cost, low maintenance, noiseless, pollution free and its capability of directly conversion from sunlight into electrical vitality. So, Commercialization of solar systems being taking place with a rapid pace all over the world. But it is protectorate on irradiation and atmospheric condition and its high capital expenses prevents us to make entire utilization of available solar energy into electricity.

Revised Manuscript Received on February 10, 2020.

* Correspondence Author

Prateek Mundra*, Electrical Engineering Department, MANIT, Bhopal, India. Email: prateekmundra93@gmail.com

Anoop Arya, Department of Electrical Engineering, MANIT, Bhopal, India. Email: anooparya.nitb@gmail.com

Suresh K Gawre, Department of Electrical Engineering, MANIT, Bhopal, India. Email: sgawre28@gmail.com

(C) The Authors. Published by Blue Eyes Intelligence Engineering and Sciences Publication (BEIESP). This is an open access article under the CC BY-NC-ND license (http://creativecommons.org/licenses/by-nc-nd/4.0/)
Generally, PV cells inside a solar module are associated in arrangement so as to get a high voltage. The arrangement association has a detriment if a solar module is mostly concealed, for instance by close by structures, passing mists or untamed life and so on halfway concealing is a critical factor that influences the power yield of a solar module, it is essential to deal with the module execution under these conditions [1]. To limit losses due to shading, parallel diodes are connected across strings. In this paper causes and effects of partial shading condition has also been discussed.

At the point when a solar framework is experiencing concealing, its $\mathrm{P}-\mathrm{V}$ characteristics features different peaks with many a local maximum and a true maximum. The regular MPPTs, like P\&O, Hill Climbing and Incremental Conductance is probably stuck at local maxima, since its calculation can't be able to distinguish between true and local peaks. Therefore, it wavers around the periphery of the wrong peak and stuck at that points only, which results in huge reduction in the PV power output.

So, for maximizing the power output of PV Panels, a new MPPT technique has been developed in this paper. This new method has its own method of approach which works on principle of continuous checking for global peak which gives a better accuracy in finding of Actual maxima. So many researches are going on simultaneously on the partial shading condition as we know dependency on the solar energy is increasing day by day and for sure it will be future of electrical energy.

\section{PARTIAL SHADING CONDITION: CAUSES AND EFFECTS}

A solar PV system contains multiple PV modules in parallel and series. The generated power from the particular PV Array is total of the power produced from each solar module.

In present scenario grid-connected PV arrays are placed at facades, roofs, or usually in cities, where partial shading phenomena may be frequent. If some of the solar cells are shaded or perhaps do not receive adequate solar irradiation, as demonstrated in Fig. 1(a), that dissipates the power produced by the other solar cells. The V-I curve of every single solar module is demonstrated in Fig. 1(b). If the solar module functions at current Ia, the shaded solar module operate in the reverse biased region and serves as a load somewhat than power source [2]. Due to this kind of high-power diffusion, heat is produced which often causes irreversible damage in order to the shaded solar modules as demonstrated in [3-4]. 


\section{Partial Shading Condition on PV Array: Causes, Effects and Shading Mitigation using DSMPPT}

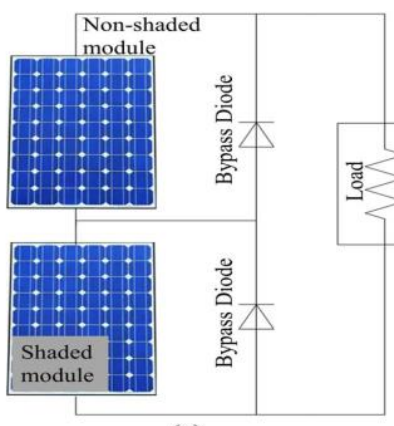

(a)

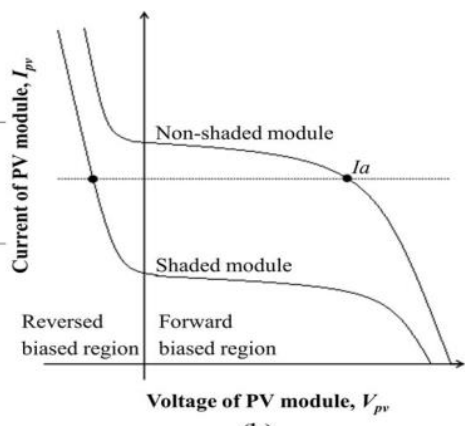

(b)
Fig. 1(a) PV array under partial shading conditions. 1(b) P-V curve of PV Modules

In [4] given everlasting damage to solar segments whose cells have substantial VBR values including inner fires, back sheet damage as demonstrated in Fig.2. To limit the reduction in power of solar module, manufacturers sum up the parallel diodes as demonstrated in Fig. 2. It defends the particular solar module from damage during partial shading [5], [6]. Throughout $[7,8]$ linked different three irradiance level modules offer three different peaks in $\mathrm{P}-\mathrm{V}$ characteristics of photovoltaic array, as demonstrated in Fig.3. PV power outcome variability having some sort of negative impact on the quality of power and reliability within the grid [9].

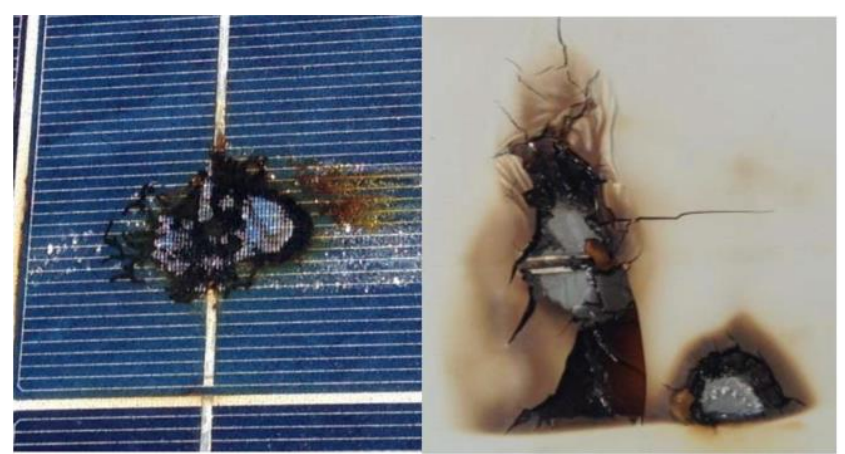

Fig. 2. Burnt cell and back sheet on a PV panel with high temperatures more than $300^{\circ} \mathrm{C}$ operating without parallel diodes under partial shading [4].

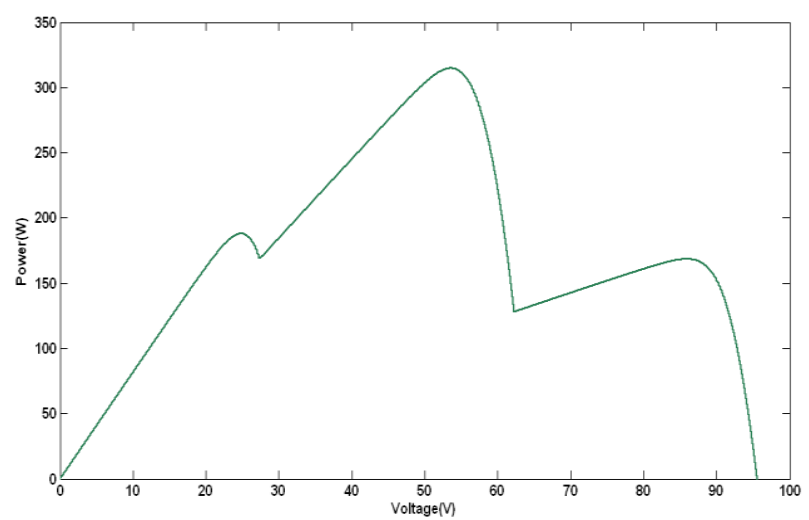

Fig. 3 P-V characteristics of 3 series connected solar module at different irradiation

\section{PV MODELING}

PV unit present a non-linear I-V characteristics with several variables that need to get adjusted from experimental info of particular devices, typically the mathematical model of the particular PV unit may end up being convenient in the analysis of the dynamic evaluation of converters, inside the review of the PV units and its components employing circuit simulator. The comparable circuit type of the particular solar cell has demonstrated in Fig.4.

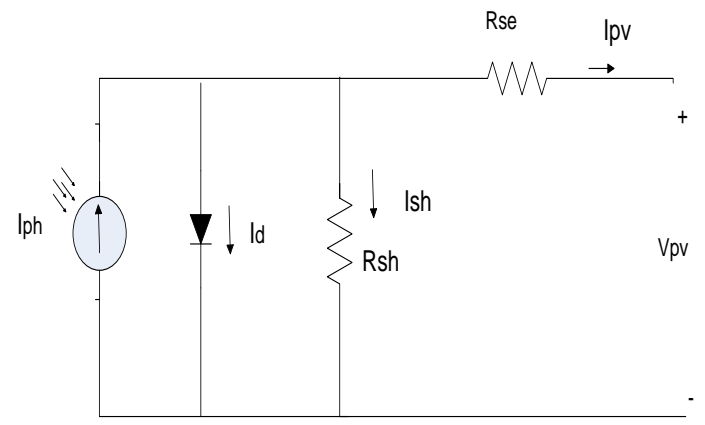

Fig.4 circuit diagram of solar cell

Photovoltaic cells are constructed by different available semiconductors by employing different manufacturing process. When light falls on the particular cell it results carriers of charge that generate an electric source, charges will be originated when energy available in incident photon has ability to break the covalent particles of the material used, and process of generation of charge by breaking covalent bonds will be affected by the used semiconductor material as well as the attributes of the light incident. Generally, the solar process can be illustrated since consumption of solar irradiation, production and movement of charge carriers at p-n terminal and storage of the electrical energy at the output of the PV system. Process of origin regarding electrical energy is dependent on the flux associated with present light source and even the ability of consumption of the semiconductor material, the ability of assimilation depends mainly on the particular semiconductor characteristics like bandgap, around the reflectance of typically the surface of cell, semiconductors carrier concentration, on mobility and temperature etc.

\section{NON-LINEAR CHARACTERISTICS OF SOLAR ARRAY UNDER SHADING EFFECTS}

The solar array is made up of several solar segments attached in series-parallel combination in order to get the required current and voltage. To shield solar segments from hot-spot issue, the parallel diodes are usually connected along with every solar segment. And even one stopping diode is definitely connected in series together with every string, which will be a bunch of sequence of connected solar segments, in order to save the modules, coming from the effect of possible difference between series attached strings. When the range of irradiance on solar array is same, only a single maximum power point is there in the $\mathrm{P}-\mathrm{V}$ characteristic of solar array.

On the other hand, because of the parallelly connected diodes numerous local peaks may be present therein $\mathrm{P}-\mathrm{V}$ curve beneath partially shaded condition as shown in Fig.5.

Published By: 

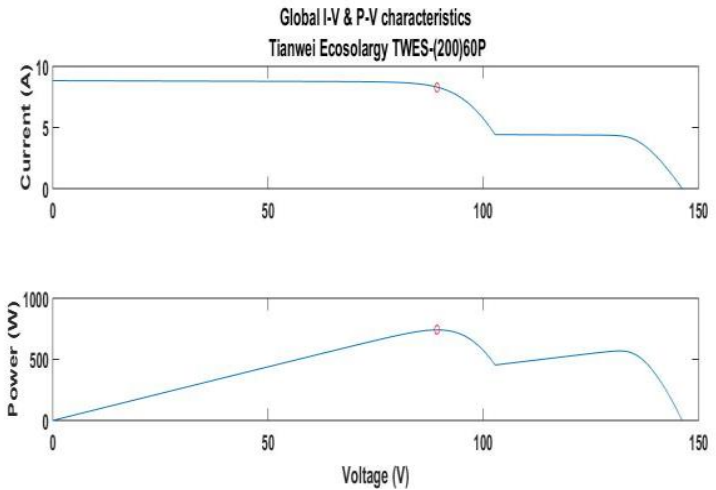

Fig.5 Nonlinearity in PV and IV characteristics of PV panel under partial shading

\section{METHODOLOGY}

Typical MPPT has been unsuccessful to get the global MPP. A few improved algorithms of MPP can observe with some sort of microprocessors and other components which is intricate. The method described throughout this paper finds the particular Global Peak with reduced components and complexity. For locating Global peak, we have used a couple of algorithms. One is Regional Peak Finding Algorithm (RPFA) other is Global Peak Finding Algorithm (GPFA). Regarding switching between these algorithms, a Director System (DS) is required.

\section{A. Regional Peak Finding Algorithm (RPFA)}

The Regional Peak Finding Algorithm (RPFA) is employed to obtain the local peak of P-V curve. We can say that the P-V characteristics from the solar panel under even insulation has a single peak in it. The Regional Peak Finding Algorithm tracks in order to find the peak associated with individual curves as it goes on. Flow-chart of the developed algorithm has been shown in the Fig. 6. The control mechanism starts by having a record of resulted power. The new result in power output is obtained simply by changing duty cycle.

Under continuously changing insolation circumstances, solar array P-V characteristics demonstrate multiple local peaks. The Regional Peak Finding Algorithm (RPFA) utilizes a mountain climbing approach that settles right around the higher point of the P-V curve.

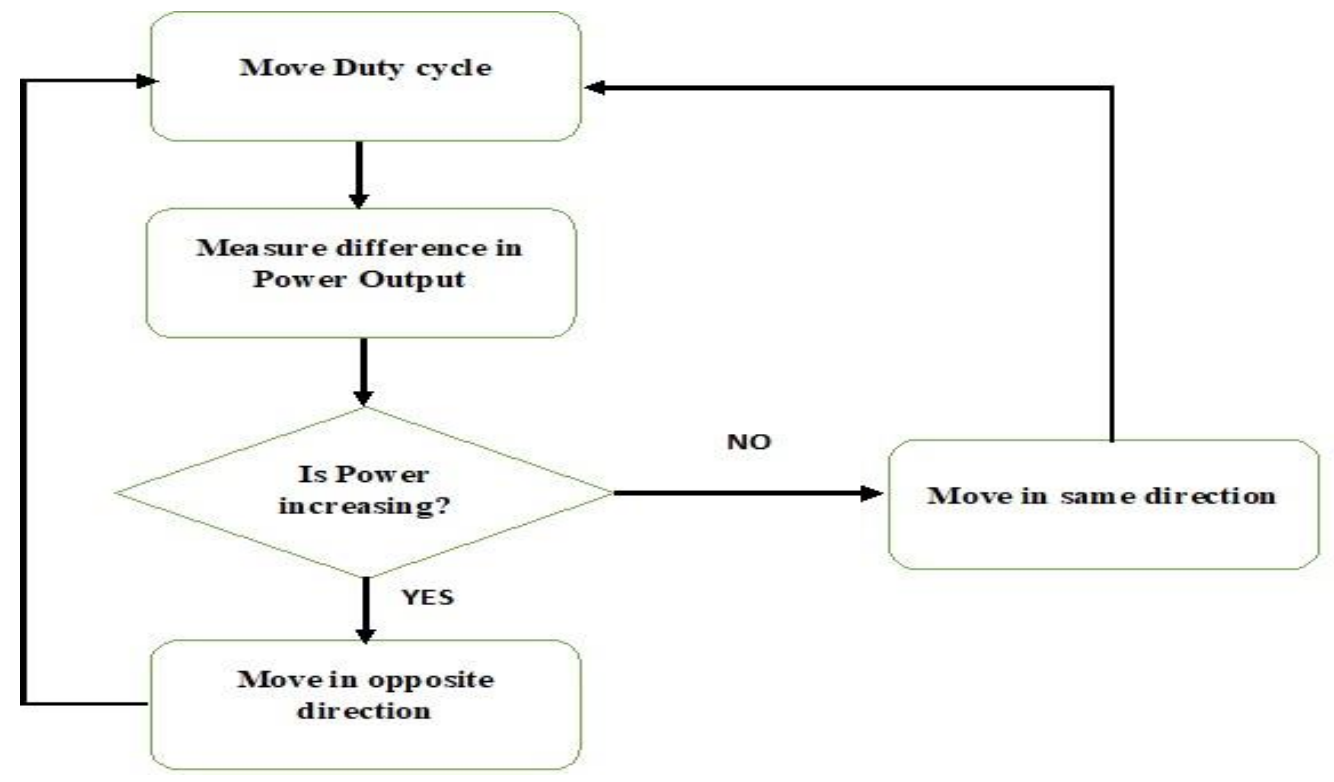

Fig.6 flowchart of RPFA

\section{B. Global Peak Finding Algorithm (GPFA)}

A unique Global Peak Finding Algorithm (GPFA) displayed in Fig.7 is essential to make sure that the regional peak finding operates across the real peak point, instead evolving around local peak. The particular algorithm glides the operating range of converter while saving the peak power output through a maxima detector. The maxima detector after that switches to the other capacitor and the operating point glide is restarted. Typically, the capacitors' voltages are regularly compared by using a comparator that trips once the second glide comes within the acceptable difference of the particular maximum power point kept with the first capacitor. The particular second glide then stops and the system comes back to the Regional Peak Finding Algorithm (RPFA). Since it is usually essential that this comparator often trips, it ought to be set in order to do so just under the peak power point to be able to allow for random noise and offset. Given that the particular trip point is sufficient to ensure that the algorithm ends about the desired peak, the Regional Peak Finding Algorithm (RPFA) will certainly zero in within the MPP. In the case regarding two peaks so near in power that if comparator trips around the wrong peak, the error is simply by definition small enough in order to be unimportant. 


\section{Partial Shading Condition on PV Array: Causes, Effects and Shading Mitigation using DSMPPT}

\section{Director System}

A director system is essential to switch converter between the regional and global algorithms. For basic functioning, the director simply demands to periodically switch with GPFA to ensure that the converter is functioning around the real peak.
Whenever the peak point is redeemed, the director will switch back to RPFA. The described process must be periodically repeated with every single timeout.

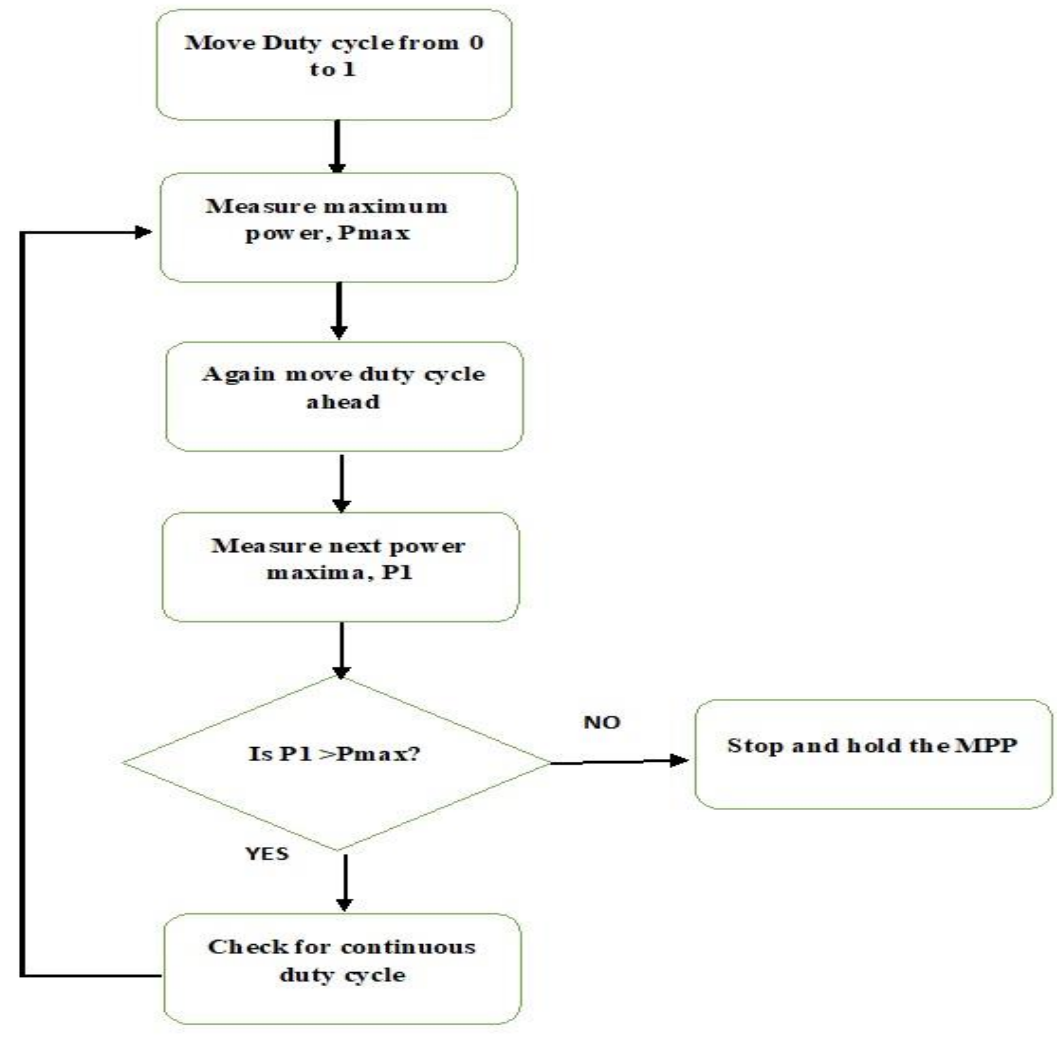

Fig.7 flowchart of GPFA

\section{RESULTS AND DISCUSSION}

Solar module under partial shading condition have been simulated using MATLAB having the three level of different solar irradiations. So, it should have three peaks in its P-V characteristics as shown in Fig.3. Results for boost converters and PV panel outputs have been shown in Fig.8 to Fig.13 as well as the result also shown in values in table 1 .

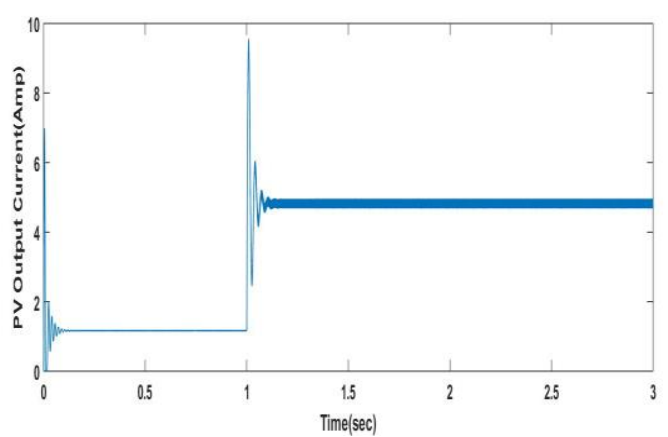

Fig.8 PV output current v/s time

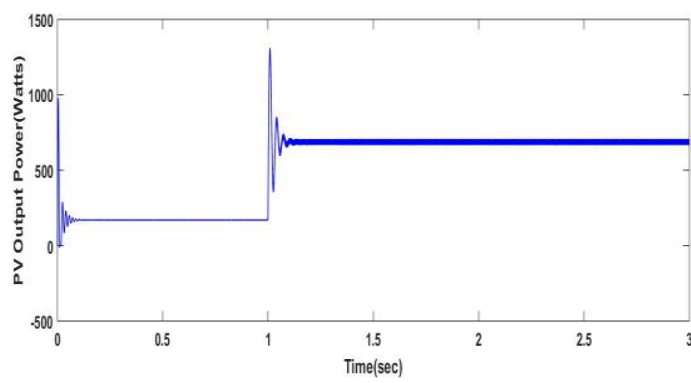

Fig.9 PV output power v/s time

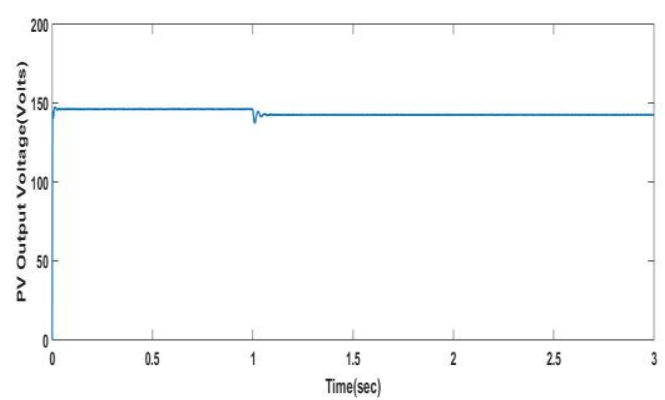

Fig.10 PV output voltage v/s time 


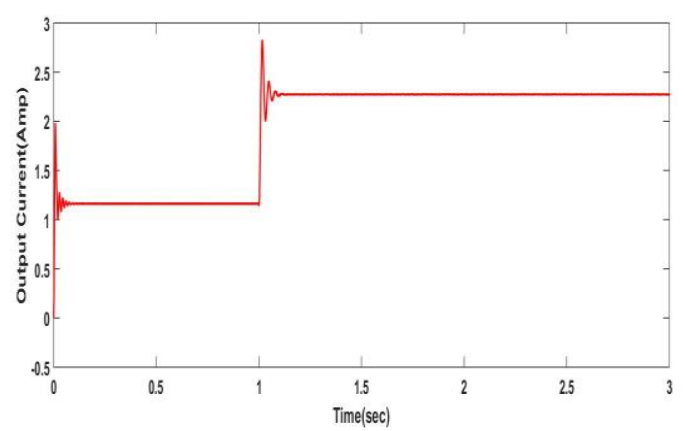

Fig.11 output current at load end v/s time

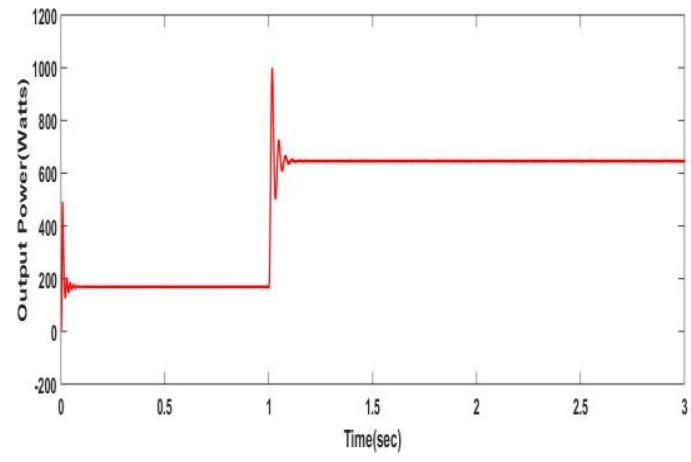

Fig.12 output power at load end v/s time

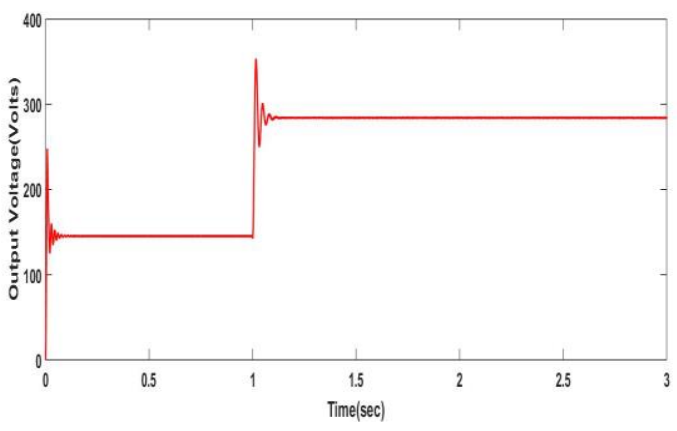

Fig.13 output voltage at load end v/s time

Final output of PV panel and at load end is tabulated in following table.

Table- I: Final output of PV panel and at load end

\begin{tabular}{|c|c|c|}
\hline Sr. No. & Parameters & Values \\
\hline 1 & Output Power at load end & $655 \mathrm{~W}$ \\
\hline 2 & Output voltage at load end & $286.1 \mathrm{~V}$ \\
\hline 3 & Output current at load end & $2.289 \mathrm{Amps}$ \\
\hline 4 & Output power of PV & $669 \mathrm{~W}$ \\
\hline 5 & Output Voltage of PV & $142.5 \mathrm{~V}$ \\
\hline 6 & Output current of PV & $4.7 \mathrm{Amps}$ \\
\hline
\end{tabular}

\section{CONCLUSION}

In this paper we have discussed about all the constraints related to partial shading conditions. This brief about the effects of non-uniform insulation of solar panel as well as their remedies like connecting bypass diode and MPPT techniques. It can be said that partial shading condition and MPPT techniques are continuously being researched, this result in so many new and modified methods to increase power output from PV system.

An existing Boost Converter Simulation with MPPT using continuous duty cycle sweep technique is actualized in MATLAB-SIMULINK. In this paper, the simulated technique can improve the dynamic and consistent state execution of the solar modules all the while. From results it is seen that the developed algorithm is able to find the true maxima in spite of variances, When the outer condition changes all of a sudden, the algorithm can follow the global power point rapidly.

\section{REFERENCES}

1. Faiza Belhachat, Cherif Larbes," Comprehensive review on global maximum power point tracking techniques for PV systems subjected to partial shading conditions", Solar Energy, Volume 183, Pages 476-500, 2019.

2. S. Fadhel, C. Delpha, D. Diallo, I. Bahri, A. Migan, M. Trabelsi, M.F. Mimouni, "PV shading fault detection and classification based on I-V curve using principal component analysis: Application to isolated PV system”, Solar Energy, Volume 179, Pages 1-10, 2019.

3. B. I. Rani, G. S. Ilango and C. Nagamani, "Enhanced Power Generation from PV Array Under Partial Shading Conditions by Shade Dispersion Using Su Do Ku Configuration," in IEEE Transactions on Sustainable Energy, vol. 4, no. 3, pp. 594-601, July 2013.

4. Kok Soon Tey, Saad Mekhilef, "Modified Incremental Conductance Algorithm for Photovoltaic System Under Partial Shading Conditions and Load Variation," Ieee Transactions on Industrial Electronics, Vol. 61, No. 10, October 2014

5. S. Mekhilef, R. Saidur, and A. Safari, "A review on solar energy use in Sharma, V. Balaji Venkateswaran and R. Singh, "Experimental Analysis of Electrical and Thermal Effects of Various Configurations of Partial Shading on Three Different Solar Module Technologies," 2018 International Conference on Recent Trends in Electrical, Control and Communication (RTECC), Malaysia, Malaysia, 2018, pp. 137-142.

6. R. Ramaprabha and B. L. Mathur, "Characteristics of solar PV array under partial shaded conditions," TENCON 2008 - 2008 IEEE Region 10 Conference, Hyderabad, 2008, pp. 1-5 doi: 10.1109/TENCON.2008.4766511

7. Z. Mao, Z. Sunan, M. Peng, S. Yanlong and Z. Weiping, "Modelling of PV module and its application for partial shading analysis - part II: partial shading analysis and simulation approach of large-scale PV array," in The Journal of Engineering, vol. 2017, no. 13, pp. 1316-1320, 2017.doi: 10.1049/joe.2017.0542

8. livarani Mohapatra, Byamakesh Nayak, Priti Das, Kanungo Barada Mohanty, "A review on MPPT techniques of PV system under partial shading condition", Renewable and Sustainable Energy Reviews, Volume 80, Pages 854-867, 2017.

9. Liqun Liu, Xiaoli Meng, Chunxia Liu, "A review of maximum power point tracking methods of PV power system at uniform and partial shading”, Renewable and Sustainable Energy Reviews, Volume 53, Pages 1500-1507, 2016.

10. Kari Lappalainen, Seppo Valkealahti "Effects of Irradiance Transitions on the Output Power Fluctuations of Different PV Array Configuration," 2016 IEEE Innovative Smart Grid Technologies - Asia (ISGT-Asia) Melbourne, Australia, Nov 28 - Dec 1, 2016

\section{AUTHORS PROFILE}

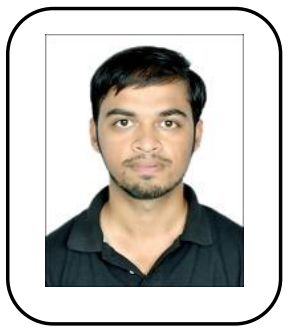

Prateek Mundra born in 1993 in India. He received his Bachelor's degree from LNCT Bhopal and MTech. degree in Power Systems from MANIT, Bhopal. Currently he is pursuing $\mathrm{PhD}$ in Electrical Engineering Department at MANIT, Bhopal. His research interest is Solar Energy, Power System Economics, Renewable Energy. 


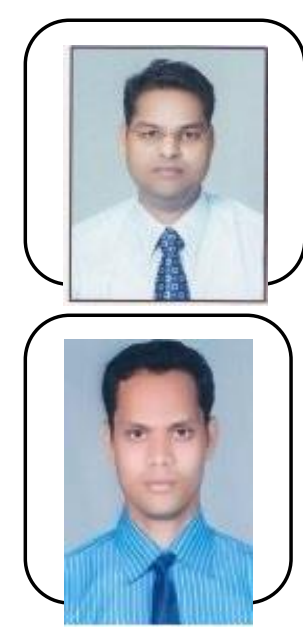

Anoop Arya has received the degree of M. Tech. in Heavy Electrical Equipment from MACT, Bhopal, India in 2006. also Ph.D. from department of electrical engineering MANIT, Bhopal. Presently, he is working as Associate professor in Electrical Engg. Deptt. At MANIT, Bhopal. His areas of interest are power System economics, distribution automation and optimization.

Suresh K. Gawre has received his B.E. (2000) and M. Tech. (2006) in Electrical Engineering and Ph.D .(2015) from MANIT (Formally MACT) Bhopal, India. He is currently working as Assistant Professor in the Department of Electrical Engineering MANIT, Bhopal. Apart from power system his area of interest is power quality analysis, monitoring and solar power integration. 